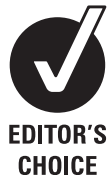

CHOICE
1 Department of Clinical

Medicine, Institute of Molecular Medicine, St James's Hospital,

Dublin, Ireland

${ }^{2}$ Department of

Haematology-Oncology, Istituto Clinico Humanitas, Rozzano, Italy

${ }^{3}$ Department of Medicine I, Medical University Vienna, Vienna, Austria ${ }^{4}$ Department of Pathology, Aberdeen University Medical School, Aberdeen, UK

\section{Correspondence to}

Professor Dr Kenneth O'Byrne, Hope Directorate, St James's Hospital, P0 Box 580, James's Street, Dublin 8, Ireland; kobyrne@stjames.ie

Accepted 3 August 2011 Published Online First 29 October 2011

\title{
The role of the molecular footprint of EGFR in tailoring treatment decisions in NSCLC
}

\author{
Kathy Gately, ${ }^{1}$ John O'Flaherty, ${ }^{1}$ Frederico Cappuzzo, ${ }^{2}$ Robert Pirker, ${ }^{3}$ Keith Kerr, ${ }^{4}$ \\ Kenneth O'Byrne ${ }^{1}$
}

\section{ABSTRACT}

The majority of patients with non-small-cell lung cancer (NSCLC) present with advanced disease, with targeted therapies providing some improvement in clinical outcomes. The epidermal growth factor receptor (EGFR) tyrosine kinase (TK) plays an important role in the pathogenesis of NSCLC. Tyrosine kinase inhibitors (TKIs), which target the EGFR TK domain, have proven to be an effective treatment strategy; however, patient responses to treatment vary considerably. Therefore, the identification of patients most likely to respond to treatment is essential to optimise the benefit of TKIs. Tumour-associated activating mutations in EGFR can identify patients with NSCLC who are likely to have a good response to TKIs. Nonetheless, the majority of patients relapse within a year of starting treatment. Studies of tumours at relapse have demonstrated expression of a T790M mutation in exon 20 of the EGFR TK domain in approximately $50 \%$ of cases. Although conferring resistance to reversible TKIs, these patients may remain sensitive to new-generation irreversible/panerb inhibitors. A number of techniques have been employed for genotypic assessment of tumourassociated DNA to identify EGFR mutations, each of which has advantages and disadvantages. This review presents an overview of the current methodologies used to identify such molecular markers. Recent developments in technology may make the monitoring of changes in patients' tumour genotypes easier in clinical practice, which may enable patients' treatment regimens to be tailored during the course of their disease, potentially leading to improved patient outcomes.

\section{BACKGROUND \\ Epidemiology of non-small-cell lung cancer}

Lung cancer is the most prevalent life-threatening cancer worldwide ${ }^{1}$ with more than $80 \%$ being nonsmall-cell lung cancer (NSCLC). Approximately $70-80 \%$ of patients with NSCLC present with locally advanced or metastatic disease and, if untreated, have a 1-year survival of $\sim 15 \%$. Palliative chemotherapy improves cancer-related symptoms and increases the 1-year survival rate by approximately $10 \%{ }^{2}$ The pathogenesis of lung cancer involves the accumulation of several molecular abnormalities over time. Alterations in gene sequence or expression can occur in the cell-signalling and regulatory pathways involved in cell-cycle control, apoptosis, proteosome regulation and angiogenesis. Genetic changes include mutations, gene silencing through epigenetics, gene amplification or deletion and whole chromosome gains or losses. Alterations in receptor tyrosine kinases
(TKs), such as the epidermal growth factor receptor (EGFR) and insulin-like growth factor receptor 1, include overexpression, amplification or mutations. ${ }^{3}$ The development of molecular targeted therapies aimed at these molecular alterations has generated great optimism for the treatment of cancers such as NSCLC, and drugs targeting the EGFR tyrosine kinase domain are now available.

\section{Targeted therapies with EGFR inhibitors}

Novel therapeutic agents, in particular those that specifically target members of the human epidermal growth factor receptor (HER (ErbB1)) pathway, have shown encouraging therapeutic efficacy. Initially, Trastuzumab (Herceptin) was approved for the treatment of HER-2 (ErbB-2)-positive breast cancer, and after its success, three EGFR (EGFR1/ErbB-1)specific agents received regulatory approval. Cetuximab (Erbitux), a chimeric monoclonal G1 (IgG1) antibody that binds to the EGFR with high affinity, was licensed to treat metastatic colorectal cancer (mCRC) and squamous cell carcinoma of the head and neck (SCCHN). ${ }^{4}$ Cetuximab added to chemotherapy improved survival in the FLEX trial $^{5}$ but failed to meet its primary endpoint of progressionfree survival assessed by the independent radiological review committee in the BMS099 Phase III trial. ${ }^{6}$ This antibody blocks ligand binding and induces receptor internalisation and degradation resulting in the downregulation of surface EGFR expression. Gefitinib (Iressa) and erlotinib (Tarceva) were licensed to treat advanced or metastatic NSCLC, and erlotinib was licensed to treat advanced or metastatic pancreatic cancer. These two EGFR tyrosine kinase inhibitors (TKIs) reversibly and specifically inhibit EGFR downstream signalling by binding to the ATP site on the kinase domain of the receptor inducing apoptosis and inhibiting growth and cell proliferation. $^{4}$

\section{EGFR pathway deregulation in NSCLC}

EGFR-TK signalling plays an essential role in the pathogenesis of many NSCLCs; EGFR protein expression is seen in up to $85 \%$ of NSCLC cases, although the prognostic relevance of EGFR in this disease remains equivocal. ${ }^{7-9}$ In general, the expression of a target protein is deemed sufficient to determine which tumours will respond to targeted cancer therapy. ${ }^{10}$ There have, however, been conflicting results regarding the value of EGFR protein expression in predicting survival benefit with TKIs. ${ }^{11}$ Several studies have failed to demonstrate a role for increased EGFR expression in predicting response of NSCLC to oral EGFR TKIs. $^{12-14}$ 
In 2004, somatic activating mutations in the EGFR TK domain were described. Mutations were either small, in-frame deletions or amino acid substitutions clustered around the ATP-binding pocket of the TK domain. These mutations were mainly found in female, never smokers with adenocarcinomas, who were of Asian ethnicity. ${ }^{1516}$ Cells harbouring these mutations become highly dependent on the constitutively active EGFR signalling pathway, a state referred to as 'oncogenic addiction'. ${ }^{17} 18$ A germline T790M EGFR mutation has been reported in a family with multiple cases of NSCLC. ${ }^{19}$ This T790M mutation has been described as an oncogenic mutation that confers a growth advantage to cancer cells. ${ }^{20} 21$ Initially, it was reported that the kinase activity of T790M mutant EGFR was similar to wild-type EGFR. ${ }^{22} 23$ However, Vikis and colleagues showed that T790M has enhanced kinase activity. ${ }^{24}$ Mulloy and colleagues showed that mutant cells harbouring both the T790M and the L858R mutations or 'double mutants' demonstrated increased tyrosine phosphorylating activity. ${ }^{25}$ The T790M mutation has also emerged as a secondary point mutation that is present in approximately half of lung cancer patients who develop resistance to EGFR TKIs (see below). ${ }^{26}$

Pinter and colleagues have shown that there is little correlation between EGFR expression, as determined by standard immunohistochemistry, and EGFR-activating mutations, increased EGFR gene copy number or response to EGFR TKI. ${ }^{10}$
This suggests that the EGFR genotype, and not immunohistochemistry, is the best method to identify NSCLC tumours that are most likely to benefit from treatment with an EGFR TKI. ${ }^{27}$

\section{Response to EGFR TKIs}

Although patients with specific EGFR gene-activating mutations are more likely to have amplified EGFR or high EGFR expression, it is the mutation status alone that predicts response to EGFR TKIs ${ }^{15} 2829$ in first-line therapy. ${ }^{30-33}$ Many mutations in exons 18-21 of the kinase domain of the EGFR gene have been identified in tumours that respond to EGFR TKIs (figure 1); however, two mutations are most common-in-frame deletions in exon 19 (del19) and a substitution mutation in exon 21 (L858R). These two mutations account for $85-90 \%$ of the drug-sensitive EGFR mutations seen in NSCLC. ${ }^{29}$ Two other sensitising mutations have been validated-substitutions in exons 18 (G719A/C) and 21 (L861O). ${ }^{36}$ In addition, activating mutations have been shown to demonstrate different sensitivities to EGFR TKIs, with exon 19 deletions being more likely to respond than those of exon 21. ${ }^{37}$ Activating mutations in EGFR are associated with improvements in PFS and overall survival (OS)..$^{38-43}$ Conversely, some substitution mutations in exon 20 (T790M) and exon 21 (T854A) are known to confer resistance to some EGFR TKIs (figure 1); ${ }^{22} 4445$ Tumours that initially respond to treatment with the EGFR TKIs erlotinib and gefitinib almost invariably develop acquired resistance to these drugs, ${ }^{22} 46$
Figure 1 Schematic of the epidermal growth factor receptor gene with locations of mutations in the tyrosine kinase (TK) domain. Adapted from Sharma et $a l^{34}$ and Shigematsu et al. ${ }^{35}$

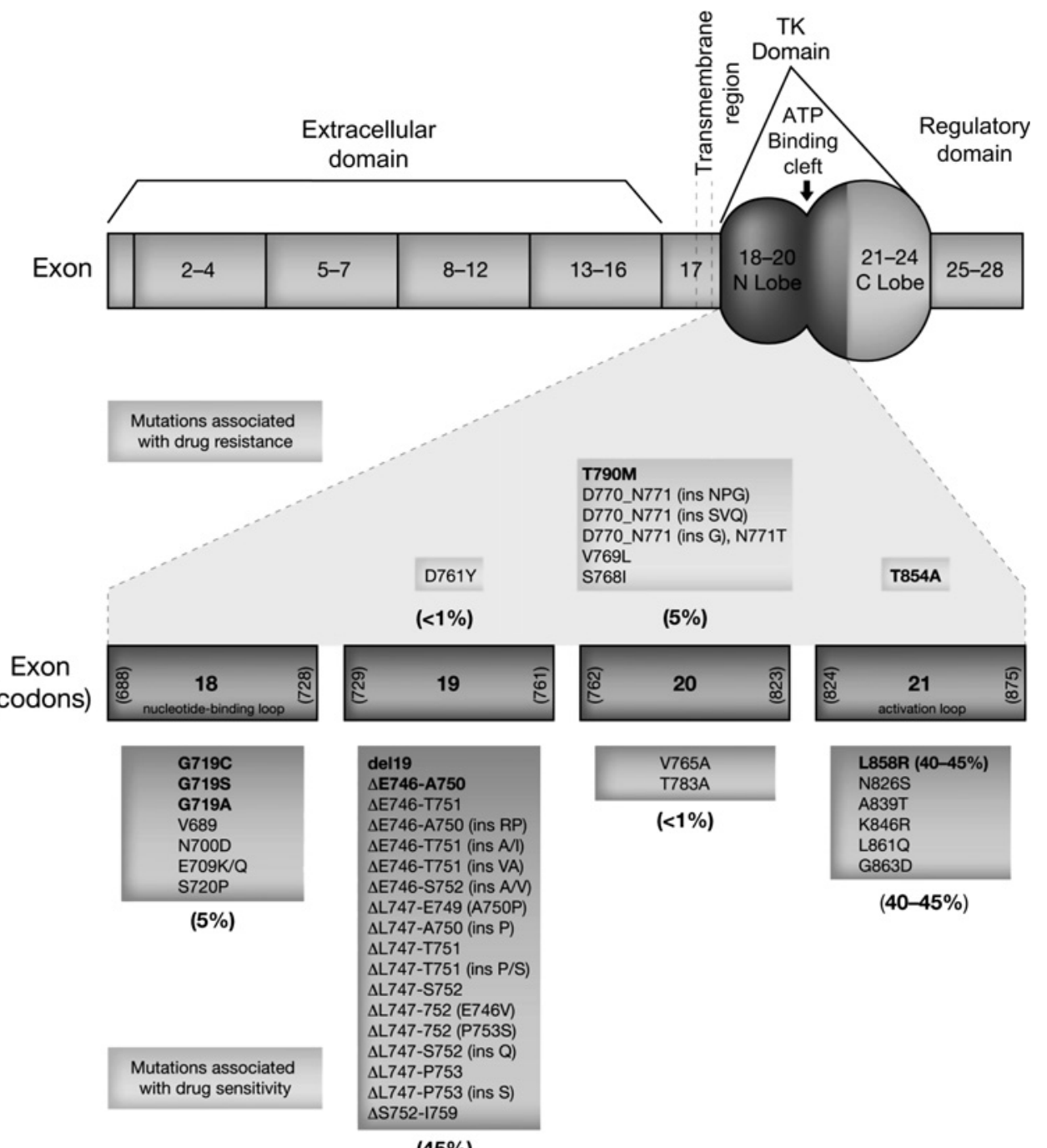

(45\%) 
which is conferred by the T790M mutation in $50 \%$ of cases. ${ }^{47-49}$ It was initially thought that the substitution of the larger methionine residue may cause steric hindrance to the binding of the drugs. ${ }^{22} 23$ A structurally similar reversible TKI is, however, able to overcome the T790M mutation. ${ }^{50}$ The T790M mutation may result in increased affinity of EGFR for ATP compared with erlotinib or gefitinib and that this is the primary mechanism by which the mutation confers drug resistance. ${ }^{51}$ Thus, it should be possible to overcome the resistance by developing TKIs that have a higher affinity for the T790M kinase. ${ }^{44} 5253 \mathrm{New}$ generation EGFR TKIs that bind irreversibly to the EGFR-TK, forming covalent cross-links with EGFR, such as afatinib (BIBW 2992), have been shown to be active against tumours resistant to reversible EGFR TKIs ${ }^{22} 52-56$ and may offer an alternative therapy strategy. In addition, owing to their irreversible binding, new-generation TKIs may have a longer duration of action than reversible agents. In order to change the therapeutic agent at the optimal time to prevent tumour progression, it would be useful to know when the T790M mutation has developed. A recent publication found T790M in up to $38 \%$ of patients not previously treated with a TKI. ${ }^{57}$ The existence of a T790M mutation in a few cancer cells at diagnosis confers a shorter time to tumour progression. ${ }^{58}$ Such cells are subsequently 'cloned out' during the patient's treatment with EGFR TKIs indicating that these patients may benefit from treatment with new-generation EGFR TKIs from the beginning. Alternatively screening for the emergence of the T790M mutation during treatment may allow early identification of acquired resistance to TKIs and treatment to be tailored as necessary.

In addition to these specific EGFR mutations, other factors such as amplification or activation of the insulin-like growth factor receptor ${ }^{59}$ and MET amplification ${ }^{60}$ have also been shown to confer resistance to EGFR TKIs. These nuances of the EGFR discussed above demonstrate that both preselection of patients most likely to respond to EGFR-targeted therapy and screening during therapy are crucial to determine the appropriate treatment regimen.

\section{Selection of patient material for detection of EGFR mutations}

The mutation status of EGFR has been determined in original tumour specimens obtained during surgical resec-

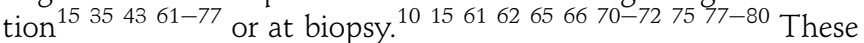
tumour specimens were stored as either paraffin-embedded tissues $^{10} \quad 15 \quad 40 \quad 42 \quad 43 \quad 61-63 \quad 65-67 \quad 70-77 \quad 81-83$ or snap-frozen samples, ${ }^{15} 35646869788485$ or analysed as fresh tissue. ${ }^{79}$ Fineneedle aspirates (FNAs), ${ }^{86-88}$ bronchial brushings, serum and plasma, circulating tumour cells (CTCs) and pleural effusion samples have also been used to assess EGFR mutation status in patients receiving EGFR TKI therapy.

Kimura and colleagues assessed EGFR mutation status using DNA extracted from serum obtained 14 days after initiation of gefitinib therapy and found this approach to be a potentially convenient means of predicting sensitivity to EGFR TKI therapy. ${ }^{65}$ Pao and colleagues assessed EGFR mutation status in three patients using DNA derived from biopsy samples and pleural effusions obtained after disease progression on EGFR TKI therapy. ${ }^{23}$ The T790M mutation was identified in all samples from these patients. The authors suggest that rebiopsy of progressive disease should become a standard procedure, especially for patients in clinical trials of targeted agents. Kosaka and colleagues assessed EGFR mutation status in 14 tumour samples obtained at the time of progression after initial response to EGFR TKI therapy. ${ }^{89}$ Seven tumours had the T790M mutation. In each of four patients in whom a T790M mutation was found in pretreatment serum DNA, EGFR TKI therapy resulted in a poor outcome. ${ }^{90}$

Whenever possible, tumour specimens should be obtained from the most easily accessible tumour tissue immediately preceding the treatment. ${ }^{11}$ In addition, close cooperation between clinicians, molecular biologists and pathologists is crucial. $^{91}$

\section{Sample quality and quantity}

Although genotypic assessment may be useful in determining which patients are likely to respond to EGFR TKI therapy, problems are associated with obtaining suitable DNA for analysis. The quality of the samples, the quality of the extracted DNA and the quantity of DNA available using current methods may limit the routine use of genotypic assessment.

As described above, cancer cells from various sources have been used for genotyping. These include archived surgically resected tissue from patients who subsequently develop recurrent or progressive disease, ${ }^{15} \quad 3543 \quad 61-77$ biopsy tissue, $^{10} 156162656671727577-80$ cytology specimens from lavage, ${ }^{80}$ pleural effusion, ${ }^{23} 727780$ an unspecified source, ${ }^{74} 75$ FNA cytology ${ }^{70} 7277-80$ (CTCs), tumour DNA in serum ${ }^{66}$ and tumour DNA in plasma ${ }^{90}$ or blood. ${ }^{57} 92$

Each of the sources described above has merits and drawbacks. The mutation status of EGFR can be determined in tumour specimens obtained during curative surgery or at biopsy. Surgery offers the best chance of high-quality and high-volume tumour tissue samples, but only $20-25 \%$ of lung cancers are suitable for curative surgery, ${ }^{93}$ and EGFR TKI therapy is only licensed for use in patients with advanced disease. There is generally only a small amount of tumour in routine diagnostic biopsy samples from patients with advanced disease, ${ }^{94}$ often only sufficient to distinguish, and possibly subtype, NSCLC from small-cell-lung cancer (SCLC) and adenocarcinoma from squamous-cell cancer. It is unclear what percentage and absolute number of tumour cells need to be present in a sample for reliable mutation detection. With the exception of laser micro-dissection, $<100$ malignant cells may be inadequate for accurate detection, and such low numbers may not be representative of a heterogeneous solid tumour. The ratio of malignant to normal cells may, however, be a more important factor, provided a minimum number are present, and a sufficiently sensitive technique is employed for mutation detection. In adenocarcinoma-bearing bronchial biopsies, the median tumour proportion is around $23 \%$; for NSCLC (not otherwise specified) cases, it is $10 \%{ }^{94}$ Manual micro-dissection is recommended for tumour enrichment in small biopsy samples. ${ }^{91}$ The following are the minimum recommended amounts of material necessary with a good probability of providing a sufficient amount of tumour for mutational analysis: at least two cylinders of tissue from a CT-guided biopsy, eight FNA passes/samples per cell block and eight smears from a brush biopsy.

Lim and colleagues were able to obtain sufficient genomic DNA for genotypic assessment from more than $80 \%$ of their 24 low-volume samples (needle or forceps biopsy or fine-needle aspiration). ${ }^{79}$ Of the 139 patients studied by Shih and colleagues, $^{72}$ only two had insufficient DNA for analysis, whereas Savic and colleagues ${ }^{80}$ successfully sequenced the DNA from $93 \%$ of their 84 cytological NSCLC specimens. Nakajima and colleagues ${ }^{70}$ determined EGFR mutation status in all 43 patients in their study, and Yoshida and colleagues ${ }^{77}$ determined EGFR mutation status in all 35 fine-needle aspiration/biopsy samples in their study. Thus, it is possible to obtain DNA from cytology-type samples, but it is questionable as to how much of 
this DNA is tumour-derived and how representative of the patient's tumour such small samples are. What is of crucial importance is that any tested sample is checked for adequacy in terms of the number and percentage of tumour cells. Two recently published studies reporting successful EGFR mutation detection from FNA cytology samples found EGFR mutation rates significantly lower than those reported from the same laboratories using tissue biopsies. ${ }^{95} 96$

Follow-up biopsy to determine T790M mutation status may be unnecessary if further research supports the initial finding that DNA sufficient for genotypic assessment can be isolated from blood samples. ${ }^{65} 8390$ Until recently, it has not been possible to obtain 'pure' CTCs, only a CTC-enriched fraction. ${ }^{97}$ However, a new method developed by Maheswaran and colleagues allows the isolation of CTCs at high purity from almost all samples tested. ${ }^{57}$ This method provided sufficient DNA for EGFR mutation analysis in 11 out of 12 patients. Although some groups have seen a $92 \%$ detection rate in CTCs, these cells are difficult to detect in NSCLC, and further validation of these techniques is necessary before implementation into routine diagnostics.

\section{Genetic analysis}

The majority of DNA analysed has been obtained from paraffinembedded tissue, ${ }^{10} 15404243$ 61-63 65-67 70-77 81-83 although some authors used frozen samples, ${ }^{15} 35646869788485$ and Lim and colleagues used fresh tissue. ${ }^{79}$ Various methods and kits have been used to extract genomic DNA. Small samples may be inadequate for genotypic assessment, as this requires significant amounts of tumour cell DNA to avoid contamination with wild-type DNA from normal cells, ${ }^{93}$ and mutation artefacts can be observed following PCR amplifications of very small amounts of DNA isolated from paraffin-embedded tissues owing to postmortem deamination of the DNA. ${ }^{98}$ This means that PCR amplification and genotypic assessment need to be repeated several times to exclude artefacts.

Although two mutations (del19 and L858R) are most commonly associated with response to EGFR TKI therapy, and one mutation with resistance (T790M), many other mutations linked to response have also been described. Genotyping by direct DNA sequencing has been used to determine EGFR mutation status and will identify any mutation, whether common or novel. Pyrosequencing, a real-time sequencing technology, using luminometric detection, permits mutation characterisation as well as the quantification of the percentage of mutated alleles in a sample. ${ }^{99}$ A recent comparative study by Querings et al demonstrated that dideoxy 'Sanger' sequencing is less sensitive than pyrosequencing. ${ }^{100}$ Mutations have been identified in DNA provided by both PCR amplification and real-time quantitative PCR (qPCR) and also in genomic DNA. ${ }^{79} 81$ Both PCR amplification $^{10} 153540424361-6871-737678-80$ 82-84 89 101-103 and qPCR 40698389104 limit the detection of mutations to those within the amplified region.

Detection by PCR is more amenable to routine use but can only be used to identify specific mutations. Several methods have been used. These include loop-hybrid PCR assay ${ }^{70}{ }^{105}$; allele-specific PCR combined with $\mathrm{PPCR}^{15}{ }^{16}$; peptide nucleic acid (PNA)-locked nucleic acid (LNA) PCR clamp ${ }^{74} 75$ 102; TaqMan assay $^{78}{ }^{106}$; restriction fragment length polymorphism $(\text { RFLP })^{107}$; common fragment analysis ${ }^{44} 77$; qPCR using the Cycleave PCR core kit and specific probes ${ }^{77} 89$; heteroduplex detection using SURVEYOR (a DNA endonuclease-digesting heteroduplex PCR product), and high-performance liquid chromatography ${ }^{108}$; and mutant-enriched PCR analysis using a restriction enzyme to specifically digest wild-type DNA. ${ }^{109}$ The EGFR gene copy number has been determined using fluorescent in situ hybridisation FISH, ${ }^{10} 408085$ chromogenic in situ hybridisation $\mathrm{CISH}^{6378} 84$ and real-time quantitative PCR. ${ }^{81}$

Kim and colleagues have compared methods for detecting mutations. ${ }^{110}$ They found that direct sequencing analysis has a relatively low sensitivity. A number of methods have been investigated to detect low-abundance mutations and increase the sensitivity of the assay. These include single-strand conformation polymorphism followed by sequencing, ${ }^{68}$ heteroduplex detection using SURVEYOR and high-performance liquid chromatography, ${ }^{108}$ and high-resolution melting analysis. ${ }^{111} 112$ These methods allow the rapid screening of large numbers of samples with high sensitivity but still need direct sequencing to confirm mutations. Single-strand conformation polymorphism analysis can detect mutations that are undetectable by direct sequencing, and heteroduplex PCR using SURVEYOR and highperformance liquid chromatography has successfully detected mutations without false negativity in formalin-fixed, paraffinembedded tissues. The scorpion amplification refractory mutation system ${ }^{66}$ and microfluidics digital $\mathrm{PCR}^{113}$ are other sensitive methods that can also be used to rapidly detect specific EGFR mutations using qPCR.

Many methods have been used to detect the 'hot-spot' mutations del19 and L858R. For clinical use, appropriate methods include fluorescence-labelled length, restriction-fragment-length polymorphism and mutant-enriched PCR analysis, which are simple and readily applicable. However, these are limited to detection of del19 and L858R mutations. Techniques using specific probes (PNA-LNA PCR clamp, qPCR) can be modified and applied to other mutations once those mutations have been identified by sequencing methods. DNA obtained from pretreatment serum cannot be used to detect all the EGFR mutations found in tumour samples, although it is a valuable option for patients without tumour samples for mutational analysis. ${ }^{66}$

At present, none of the mutational analysis techniques described above can detect all possible mutations at the necessary sensitivity. Therefore, a small percentage of mutation positive patients, who may benefit from EGFR TKIs, may be missed. However, a recent development in Taqman PCR technology has enabled the detection of EGFR DNA mutations, even within abundant backgrounds of normal material. These assays, based on competitive allele-specific TaqMan PCR or CastPCR, are sensitive enough to detect single mutant molecules in a background of 1 million normal copies. ${ }^{114}$ This is at least a 10 -fold greater sensitivity than currently available mutation-detection assays. CastPCR combines allele-specific TaqMan primers and allele-specific minor groove binder blockers in order to suppress non-specific amplification from wild-type alleles. These assays are currently being validated by us and other early-access customers, and the results are eagerly awaited.

\section{Logistics and infrastructure}

Since the licensing of gefitinib in 2009, the NHS in the UK and the INCa/Ministry of Health in France have set up national programmes for EGFR gene-mutation screening in patients with locally advanced or metastatic NSCLC. The identification of patients who are most likely to benefit from EGFR TKIs has resulted in substantial savings to healthcare systems worldwide. As the treatment of NSCLC moves from an empirical approach to molecular-based and personalised therapies, similar screening systems may be implemented for other biomarkers in the future.

It is crucial for each cancer centre/hospital to implement a strict policy for EGFR mutation screening for NSCLC 
patients. $^{91}$ The two main issues to be considered are (1) which samples to test and (2) where the testing should be carried out. Both the pathologist and the oncologist play a role in deciding which patients should be tested. Where a certain diagnosis of large cell neuroendocrine carcinoma (LCNEC), mucinous adenocarcinoma or carcinoid tumour is made, testing is not necessary. The incidence of EGFR mutations in squamous cell cancer is also low, and as a result, routine testing is not performed in many centres. Nonetheless, if a squamous carcinoma occurs in a non-smoker or where there is any doubt about tumour type, testing is reasonable. Samples suitable for testing are those that have been fixed immediately after procurement and have an adequate number of tumour cells present (see above). Manual micro-dissection to enrich samples for tumour may be necessary.

Ideally, testing would be carried out in the same centre, where the patient has been pathologically diagnosed. Testing should be carried out in an accredited laboratory following standard operating procedures, including pathological assessment of the sample prior to testing. These measures considerably reduce the risk of contamination and enable greater accuracy and reproducibility of results. On-site testing is only viable in centres where there is an adequate throughput of patients to be tested, to ensure assay efficiency, and where the appropriate equipment and technical/pathological expertise are available. Depending on the assay used for screening, either a first- or second-generation sequencer or a real-time PCR system is necessary. Where any of these criteria are not fulfilled, it may be more cost-effective to outsource the testing to another centre. The main difficulties for outsourcing testing are the logistics and delays involved in getting the samples delivered.

There is a real need for a rapid, sensitive and low-cost assay for EGFR screening. The majority of groups are currently using either direct sequencing or the Scorpion ARMs assay for mutation screening. Depending on the assay used for EGFR mutation screening, the turnaround time can vary-a realistic time is $5-7$ working days. Direct sequencing is thought to be less sensitive and more time-consuming than the Scorpion ARMs assay. The Scorpion ARMs assay requires batching of samples, which may cause delays in the turnaround time of the assay. Newer tests, such as EGFR mutation-specific antibodies, are promising. ${ }^{115} 116$ They might help to conserve tissue, which is of importance, given the emergence of other predictive biomarkers. Immunohistochemical analysis is also quick, cost-effective and routinely carried out in all pathology laboratories.

\section{Translation to the clinic}

In order to successfully treat NSCLC with TKIs, it is important to identify those patients who are likely to respond to treatment. Mutations in EGFR have been identified that are sensitising, or which confer resistance to treatment. Knowledge of such mutations may enable the physician to create individual treatment regimens based on their knowledge of their patients' genotypes. This review has presented the methods used for genotypic assessment of tumour-associated DNA to identify such EGFR mutations, each of which has advantages and disadvantages. The major problem with this type of analysis has been obtaining suitable DNA, in terms of both quality and quantity. A new method that allows isolation of CTCs from the blood of patients with lung cancer could potentially provide enough DNA for molecular analysis of mutations. ${ }^{57}$ This method could be a step forward and may enable patients' treatment regimens to be adjusted over the course of their disease by monitoring changes in their tumour genotypes during treatment.

\section{Take-home messages}

The identification of patients most likely to respond to EGFR-TKI therapy is essential to optimise the benefit of these agents for the treatment of NSCLC. Tumour-associated activating mutations in EGFR increase the sensitivity of a tumour to EGFR-TKI therapy; however, the presence of additional mutations confer resistance to reversible drugs. The identification of molecular markers of response is therefore of scientific and clinical interest. Various methodologies are used to identify such molecular markers and observe how a tumour genotype can change over time; these technological developments may enable patients' treatment regimens to be tailored during the course of their disease, potentially leading to improved patient outcomes.

Acknowledgements The authors would like to acknowledge the enormous help they received from P C Tec Kuan (Head of Department of Ophthalmology, National University Health System, Singapore). Peer-reviewer suggestions: W Eberhardt: Department of Medicine (Cancer Research), West German Tumour Centre, University Hospital of University Duisburg-Essen, Essen, Germany (wilfried. eberhardt@uni-due.de). C Manegold: University Medical Center Mannheim, Heidelberg University, Mannheim, Germany (prof.manegold@t-online.de). R Dziadziuszko: Department of Oncology and Radiotherapy, Medical University of Gdansk, Poland (rafald@amg.gda.pl). M Taron: Catalan Institute of Oncology; Hospital Germans Trias i Pujol, Badalona, Spain (mtaron@ico.scs.es).

Funding This manuscript was supported by Boehringer Ingelheim. The authors would like to acknowledge the editorial assistance of Ogilvy Healthworld. Boehringer Ingelheim provided financial support to Ogilvy Healthworld for this assistance.

Competing interests FC has received speaker's fees from Merck Serono, Roche and AstraZeneca, and honoraria for Advisory Boards from Merck Serono, Roche, Boehringer Ingelheim and AstraZeneca. RP has received speaker's fees and/or honoraria from Roche, AstraZeneca, Boehringer-Ingelheim and Merck Serono. KK has received honoraria and/or consultancy fees from Eli Lilly, Roche-Genentech-OSI, Astra Zeneca, GlaxoSmithKline, Boehringer Ingelheim. KO'B has participated on advisory boards and received speaker's fees from Boehringer Ingelheim, Eli Lilly, Roche-Genetech, AstraZeneca, Amgen, Clovis and Merck-Serono.

Provenance and peer review Not commissioned; externally peer reviewed.

\section{REFERENCES}

1. WHO. Cancer. Fact Sheet 297. 2006. http://www.who.int/mediacentre/factsheets/ fs297/en/index.html.

2. NSCLC Meta-Analyses Collaborative Group. Chemotherapy in addition to supportive care improves survival in advanced non-small-cell lung cancer: a systematic review and meta-analysis of individual patient data from 16 randomized controlled trials. J Clin Oncol 2008;26:4617-25.

3. Molina JR, Yang P, Cassivi SD, et al. Non-small cell lung cancer: epidemiology, risk factors, treatment, and survivorship. Mayo Clin Proc 2008;83:584-94.

4. Rocha-Lima CM, Soares HP, Raez LE, et al. EGFR targeting of solid tumors. Cancer Control 2007;14:295-304.

5. Pirker R, Pereira JR, Szczesna A, et al. Cetuximab plus chemotherapy in patients with advanced non-small-cell lung cancer (FLEX): an open-label randomised phase III trial. Lancet 2009;373:1525-31.

6. Lynch TJ, Patel T, Dreisbach L, et al. Cetuximab and first-line taxane/ carboplatin chemotherapy in advanced non-small-cell lung cancer: results of the randomized multicenter phase III trial BMS099. J Clin Oncol 2010;28:911-17.

7. Nicholson RI, Gee JM, Harper ME. EGFR and cancer prognosis. Eur J Cancer 2001;37(Suppl 4):S9-15

8. Cox G, Jones JL, Andi A, et al. A biological staging model for operable non-small cell lung cancer. Thorax 2001;56:561-6.

9. Pirker R, Filipits M. Targeted therapies in lung cancer. Curr Pharm Des 2009;15:188-206.

10. Pinter F, Papay J, Almasi A, et al. Epidermal growth factor receptor (EGFR) high gene copy number and activating mutations in lung adenocarcinomas are not consistently accompanied by positivity for EGFR protein by standard immunohistochemistry. J Mol Diagn 2008;10:160-8.

11. Hirsch FR, Varella-Garcia M, Cappuzzo F. Predictive value of EGFR and HER2 overexpression in advanced non-small-cell lung cancer. Oncogene 2009;28(Suppl 1): S32-7. 
12. Bailey R, Kris M, Wolf M, et al. Gefitinib ('Iressa,' ZD1839) monotherapy for pretreated advanced non-small-cell lung cancer in IDEAL 1 and 2: tumor response is not clinically relevantly predictable from tumor EGFR membrane staining alone. Lung Canc 2003:41(Suppl 2):S71.

13. Cappuzzo F, Gregorc V, Rossi E, et al. Gefitinib in pretreated non-small-cell lung cancer (NSCLC): analysis of efficacy and correlation with HER2 and epidermal growth factor receptor expression in locally advanced or metastatic NSCLC. J Clin Oncol 2003;21:2658-63.

14. Parra HS, Cavina R, Latteri F, et al. Analysis of epidermal growth factor receptor expression as a predictive factor for response to gefitinib ('Iressa', ZD1839) in nonsmall-cell lung cancer. Br J Cancer 2004;91:208-12.

15. Lynch TJ, Bell DW, Sordella R, et al. Activating mutations in the epidermal growth factor receptor underlying responsiveness of non-small-cell lung cancer to gefitinib. N Engl J Med 2004;350:2129-39.

16. Paez JG, Jänne PA, Lee JC, et al. EGFR mutations in lung cancer: correlation with clinical response to gefitinib therapy. Science 2004;304:1497-500.

17. Gazdar AF, Shigematsu H, Herz J, et al. Mutations and addiction to EGFR: the Achilles 'heal' of lung cancers? Trends Mol Med 2004:10:481-6.

18. Weinstein IB, Joe A. Oncogene addiction. Cancer Res 2008;68:3077-80; discussion 80

19. Li X, Hemminki K. Inherited predisposition to early onset lung cancer according to histological type. Int J Cancer 2004;112:451-7.

20. Regales L, Balak MN, Gong Y, et al. Development of new mouse lung tumor models expressing EGFR T790M mutants associated with clinical resistance to kinase inhibitors. PLoS One 2007:2:e810.

21. Suda K, Onozato R, Yatabe Y, et al. EGFR T790M mutation: a double role in lung cancer cell survival? J Thorac Oncol 2009;4:1-4.

22. Kobayashi S, Boggon TJ, Dayaram T, et al. EGFR mutation and resistance of nonsmall-cell lung cancer to gefitinib. N Engl J Med 2005;352:786-92.

23. Pao W, Miller VA, Politi KA, et al. Acquired resistance of lung adenocarcinomas to gefitinib or erlotinib is associated with a second mutation in the EGFR kinase domain. PLoS Med 2005;2:e73

24. Vikis $\mathbf{H}$, Sato $\mathrm{M}$, James $\mathrm{M}$, et al. EGFR-T790M is a rare lung cancer susceptibility allele with enhanced kinase activity. Cancer Res 2007:67:4665-70.

25. Mulloy R, Ferrand A, Kim Y, et al. Epidermal growth factor receptor mutants from human lung cancers exhibit enhanced catalytic activity and increased sensitivity to gefitinib. Cancer Res 2007;67:2325-30.

26. Blencke S, Ullrich A, Daub H. Mutation of threonine 766 in the epidermal growth factor receptor reveals a hotspot for resistance formation against selective tyrosine kinase inhibitors. J Biol Chem 2003;278:15435-40.

27. John T, Liu G, Tsao MS. Overview of molecular testing in non-small-cell lung cancer: mutational analysis, gene copy number, protein expression and other biomarkers of EGFR for the prediction of response to tyrosine kinase inhibitors. Oncogene 2009;28(Suppl 1):S14-23.

28. Pao W, Miller V, Zakowski M, et al. EGF receptor gene mutations are common in lung cancers from 'never smokers' and are associated with sensitivity of tumors to gefitinib and erlotinib. Proc Natl Acad Sci U S A 2004:101:13306-11.

29. Riely GJ, Politi KA, Miller VA, et al. Update on epidermal growth factor receptor mutations in non-small cell lung cancer. Clin Cancer Res 2006;12:7232-41.

30. Inoue A, Kobayashi K, Usui K, et al. First-line gefitinib for patients with advanced non-small-cell lung cancer harboring epidermal growth factor receptor mutations without indication for chemotherapy. J Clin Oncol 2009:27:1394-400.

31. Mitsudomi T, Morita S, Yatabe Y, et al. Gefitinib versus cisplatin plus docetaxel in patients with non-small-cell lung cancer harbouring mutations of the epidermal growth factor receptor (WJTOG3405): an open label, randomised phase 3 trial. Lancet Oncol 2010:11:121-8.

32. Inoue A, Kobayashi K, Maemondo M, et al. A randomized phase III study comparing gefitinib with carboplatin (CBDCA) plus paclitaxel (TXL) for the first-line treatment of non-small cell lung cancer (NSCLC) with sensitive EGFR mutations: NEJ002 study. Eur J Cancer Supp/ 2009;7:Abstract 9 LBA.

33. Lee J, Park K, Kim SW. A randomized phase III study of gefinitib (IRESSATM) versus standard chemotherapy (gemcitabane plus cisplatin) as a first-line treatment for never smokers with advanced or metastatic adenocarcinoma of the lung. 13th World Conference on Lung Cancer. San Francisco, J Thorac Oncol 2009:4(Suppl 1):S283-4.

34. Sharma SV, Bell DW, Settleman J, et al. Epidermal growth factor receptor mutations in lung cancer. Nat Rev Cancer 2007:7:169-81.

35. Shigematsu H, Lin L, Takahashi T, et al. Clinical and biological features associated with epidermal growth factor receptor gene mutations in lung cancers. J Natl Cancer Inst 2005:97:339-46.

36. Cappuzzo F. EGFR FISH versus mutation: different tests, different end-points. Lung Canc 2008:60:160-5

37. Porta R, Queralt C, Cardenal F, et al. Erlotinib customization based on epidermal growth factor receptor (EGFR) mutations in stage IV non-small-cell lung cancer (NSCLC) patients (p). J Clin Oncol 2008:26:Abstract 8038.

38. Mok TS, Wu YL, Thongprasert S, et al. Gefitinib or carboplatin-paclitaxel in pulmonary adenocarcinoma. N Engl J Med 2009;361:947-57.

39. Rosell R, Perez-Roca L, Sanchez JJ, et al. Customized treatment in non-small-cell lung cancer based on EGFR mutations and BRCA1 mRNA expression. PLoS One 2009; : 55133

40. Cappuzzo F, Hirsch FR, Rossi E, et al. Epidermal growth factor receptor gene and protein and gefitinib sensitivity in non-small-cell lung cancer. J Natl Cancer Inst 2005;97:643-55
41. Cortes-Funes H, Gomez C, Rosell R, et al. Epidermal growth factor receptor activating mutations in Spanish gefitinib-treated non-small-cell lung cancer patients. Ann Oncol 2005;16:1081-6.

42. Han SW, Kim TY, Hwang PG, et al. Predictive and prognostic impact of epidermal growth factor receptor mutation in non-small-cell lung cancer patients treated with gefitinib. J Clin Oncol 2005:23:2493-501.

43. Takano T, Ohe $\mathrm{Y}$, Sakamoto $\mathrm{H}$, et al. Epidermal growth factor receptor gene mutations and increased copy numbers predict gefitinib sensitivity in patients with recurrent non-small-cell lung cancer. J Clin Oncol 2005;23:6829-37.

44. Pao W, Miller VA. Epidermal growth factor receptor mutations, small-molecule kinase inhibitors, and non-small-cell lung cancer: current knowledge and future directions. J Clin Oncol 2005:23:2556-68.

45. Bean J, Riely G, Balak M, et al. Acquired resistance to epidermal growth factor receptor (EGFR) kinase inhibitors associated with a novel T854A mutation in a patient with EGFR-mutant lung adenocarcinoma. American Society of Clinical Oncology. Chicago, IL, 2008

46. Li D. Shimamura T, Ji H, et al. Bronchial and peripheral murine lung carcinomas induced by T790M-L858R mutant EGFR respond to HKI-272 and rapamycin combination therapy. Cancer Cell 2007;12:81-93.

47. Balak MN, Gong Y, Riely GJ, et al. Novel D761Y and common secondary T790M mutations in epidermal growth factor receptor-mutant lung adenocarcinomas with acquired resistance to kinase inhibitors. Clin Cancer Res 2006;12:6494-501.

48. Johnson BE, Jackman D, Janne PA. Impact of EGFR mutations on treatment of non-small cell lung cancer. Canc Chemother Pharmacol 2006;58(Suppl 7):5-9.

49. Gazdar AF. Activating and resistance mutations of EGFR in non-small-cell lung cancer: role in clinical response to EGFR tyrosine kinase inhibitors. Oncogene 2009:28(Suppl 1):S24-31.

50. Gendreau SB, Ventura R, Keast P, et al. Inhibition of the T790M gatekeeper mutant of the epidermal growth factor receptor by EXEL-7647. Clin Cancer Res 2007:13:3713-23.

51. Yun CH, Mengwasser KE, Toms AV, et al. The T790M mutation in EGFR kinase causes drug resistance by increasing the affinity for ATP. Proc Natl Acad Sci U S A 2008:105:2070-5.

52. Kobayashi S, Ji H, Yuza Y, et al. An alternative inhibitor overcomes resistance caused by a mutation of the epidermal growth factor receptor. Cancer Res 2005:65:7096-101.

53. Kwak EL, Sordella R, Bell DW, et al. Irreversible inhibitors of the EGF receptor may circumvent acquired resistance to gefitinib. Proc Natl Acad Sci U S A 2005; 102:7665-70

54. Li D, Ambrogio L, Shimamura T, et al. BIBW2992, an irreversible EGFR/HER2 inhibitor highly effective in preclinical lung cancer models. Oncogene 2008;27:4702-11

55. Carter TA, Wodicka LM, Shah NP, et al. Inhibition of drug-resistant mutants of ABL, KIT, and EGF receptor kinases. Proc Natl Acad Sci U S A 2005:102:11011-16.

56. Regales L, Gong Y, Shen R, et al. Dual targeting of EGFR can overcome a major drug resistance mutation in mouse models of EGFR mutant lung cancer. J Clin Invest 2009;119:3000-10

57. Maheswaran S, Sequist LV, Nagrath S, et al. Detection of mutations in EGFR in circulating lung-cancer cells. N Engl J Med 2008;359:366-77.

58. Inukai M, Toyooka $S$, Ito $S$, et al. Presence of epidermal growth factor receptor gene T790M mutation as a minor clone in non-small cell lung cancer. Cancer Res 2006:66:7854-8.

59. Guix M, Faber AC, Wang SE, et al. Acquired resistance to EGFR tyrosine kinase inhibitors in cancer cells is mediated by loss of IGF-binding proteins. J Clin Invest 2008:118:2609-19.

60. Engelman JA, Zejnullahu K, Mitsudomi T, et al. MET amplification leads to gefitinib resistance in lung cancer by activating ERBB3 signaling. Science 2007:316:1039-43.

61. Asahina H, Yamazaki K, Kinoshita I, et al. A phase II trial of gefitinib as first-line therapy for advanced non-small cell lung cancer with epidermal growth factor receptor mutations. Br J Cancer 2006;95:998-1004.

62. Chou TY, Chiu CH, Li LH, et al. Mutation in the tyrosine kinase domain of epidermal growth factor receptor is a predictive and prognostic factor for gefitinib treatment in patients with non-small cell lung cancer. Clin Cancer Res 2005;11:3750-7.

63. Giaccone G, Gallegos Ruiz M, Le Chevalier T, et al. Erlotinib for frontline treatment of advanced non-small cell lung cancer: a phase II study. Clin Cancer Res 2006; 12:6049-55.

64. Huang SF, Liu HP, Li LH, et al. High frequency of epidermal growth factor receptor mutations with complex patterns in non-small cell lung cancers related to gefitinib responsiveness in Taiwan. Clin Cancer Res 2004;10:8195-203.

65. Kimura H, Kasahara K, Shibata K, et al. EGFR mutation of tumor and serum in gefitinib-treated patients with chemotherapy-naive non-small cell lung cancer J Thorac Oncol 2006;1:260-7.

66. Kimura H, Kasahara K, Kawaishi M, et al. Detection of epidermal growth factor receptor mutations in serum as a predictor of the response to gefitinib in patients with non-small-cell lung cancer. Clin Cancer Res 2006:12:3915-21.

67. Lee CP, Taylor NJ, Attard G, et al. A Phase I study of BIBF 1120, an orally active triple angiokinase inhibitor (VEGFR, PDGFR, FGFR) given continuously to patients with advanced solid tumours, incorporating dynamic contrast enhanced magnetic resonance imaging (DCE-MRI). MOGA/FRO Annual Scientific Meeting. Sanctuary Cove, Queensland, 2006:9-12. 
68. Marchetti A, Martella C, Felicioni L, et al. EGFR mutations in non-small-cell lung cancer: analysis of a large series of cases and development of a rapid and sensitive method for diagnostic screening with potential implications on pharmacologic treatment. J Clin Oncol 2005;23:857-65.

69. Mitsudomi T, Kosaka T, Endoh H, et al. Mutations of the epidermal growth factor receptor gene predict prolonged survival after gefitinib treatment in patients with non-small-cell lung cancer with postoperative recurrence. J Clin Oncol 2005;23:2513-20.

70. Nakajima T, Yasufuku K, Suzuki M, et al. Assessment of epidermal growth factor receptor mutation by endobronchial ultrasound-guided transbronchial needle aspiration. Chest 2007:132:597-602.

71. Niho S, Kubota K, Goto K, et al. First-line single agent treatment with gefitinib in patients with advanced non-small-cell lung cancer: a phase II study. J Clin Oncol 2006;24:64-9.

72. Shih JY, Gow CH, Yu CJ, et al. Epidermal growth factor receptor mutations in needle biopsy/aspiration samples predict response to gefitinib therapy and survival of patients with advanced nonsmall cell lung cancer. Int J Cancer 2006;118:963-9.

73. Sunaga N, Tomizawa $Y$, Yanagitani N, et al. Phase II prospective study of the efficacy of gefitinib for the treatment of stage III/IV non-small cell lung cancer with EGFR mutations, irrespective of previous chemotherapy. Lung Cancer 2007:56:383-9.

74. Sutani A, Nagai Y, Udagawa K, et al. Gefitinib for non-small-cell lung cancer patients with epidermal growth factor receptor gene mutations screened by peptide nucleic acid-locked nucleic acid PCR clamp. Br J Cancer 2006:95:1483-9.

75. Tanaka T, Nagai Y, Miyazawa H, et al. Reliability of the peptide nucleic acid-locked nucleic acid polymerase chain reaction clamp-based test for epidermal growth factor receptor mutations integrated into the clinical practice for non-small cell lung cancers. Cancer Sci 2007;98:246-52.

76. Yang $\mathbf{C H}$, Shih JY, Chen KC, et al. Survival outcome and predictors of gefitinib antitumor activity in East Asian chemonaive patients with advanced nonsmall cell lung cancer. Cancer 2006;107:1873-82.

77. Yoshida K, Yatabe Y, Park JY, et al. Prospective validation for prediction of gefitinib sensitivity by epidermal growth factor receptor gene mutation in patients with nonsmall cell lung cancer. J Thorac Oncol 2007:2:22-8.

78. Hsieh MH, Fang YF, Chang WC, et al. Complex mutation patterns of epidermal growth factor receptor gene associated with variable responses to gefitinib treatment in patients with non-small cell lung cancer. Lung Cancer 2006;53:311-22

79. Lim EH, Zhang SL, Yu K, et al. An alternative approach to determining therapeutic choices in advanced non-small cell lung carcinoma (NSCLC): maximizing the diagnostic procedure and the use of low-volume lung biopsies. J Thorac Oncol 2007;2:387-96.

80. Savic S, Tapia C, Grilli B, et al. Comprehensive epidermal growth factor receptor gene analysis from cytological specimens of non-small-cell lung cancers. $\mathrm{Br} \mathrm{J}$ Cancer 2008;98:154-60.

81. Bell DW, Lynch TJ, Haserlat SM, et al. Epidermal growth factor receptor mutations and gene amplification in non-small-cell lung cancer: molecular analysis of the IDEAL/INTACT gefitinib trials. J Clin Oncol 2005:23:8081-92.

82. Eberhard DA, Johnson BE, Amler LC, et al. Mutations in the epidermal growth factor receptor and in KRAS are predictive and prognostic indicators in patients with non-small-cell lung cancer treated with chemotherapy alone and in combination with erlotinib. J Clin Oncol 2005;23:5900-9.

83. Kim KS, Jeong JY, Kim YC, et al. Predictors of the response to gefitinib in refractory non-small cell lung cancer. Clin Cancer Res 2005:11:2244-51.

84. Chang JW, Liu HP, Hsieh MH, et al. Increased epidermal growth factor receptor (EGFR) gene copy number is strongly associated with EGFR mutations and adenocarcinoma in non-small cell lung cancers: a chromogenic in situ hybridization study of 182 patients. Lung Cancer 2008;61:328-39.

85. Sequist LV, Martins RG, Spigel D, et al. First-line gefitinib in patients with advanced non-small-cell lung cancer harboring somatic EGFR mutations. J Clin Oncol 2008:26:2442-9.

86. Boldrini L, Ali G, Gisfredi S, et al. Epidermal growth factor receptor and K-RAS mutations in 411 lung adenocarcinoma: a population-based prospective study. Oncol Rep 2009;22:683-91.

87. Smouse JH, Cibas ES, Jänne PA, et al. EGFR mutations are detected comparably in cytologic and surgical pathology specimens of nonsmall cell lung cancer. Cancer 2009;117:67-72

88. Smith GD, Chadwick BE, Willmore-Payne C, et al. Detection of epidermal growth factor receptor gene mutations in cytology specimens from patients with non-small cell lung cancer utilising high-resolution melting amplicon analysis. J Clin Pathol 2008;61:487-93

89. Kosaka T, Yatabe $\mathrm{Y}$, Endoh $\mathrm{H}$, et al. Analysis of epidermal growth factor receptor gene mutation in patients with non-small cell lung cancer and acquired resistance to gefitinib. Clin Cancer Res 2006;12:5764-9.
90. Mack PC, Holland WS, Burich RA, et al. EGFR mutations detected in plasma are associated with patient outcomes in erlotinib plus docetaxel-treated non-small cell lung cancer. J Thorac Oncol 2009;4:1466-72.

91. Pirker R, Herth FJ, Kerr KM, et al. Consensus for EGFR mutation testing in non-small cell lung cancer: results from a European workshop. J Thorac Oncol 2010;5:1706-13.

92. Nagrath S, Sequist LV, Maheswaran S, et al. Isolation of rare circulating tumour cells in cancer patients by microchip technology. Nature 2007:450:1235-9.

93. Daniele L, Macri L, Schena $\mathbf{M}$, et al. Predicting gefitinib responsiveness in lung cancer by fluorescence in situ hybridization/chromogenic in situ hybridization analysis of EGFR and HER2 in biopsy and cytology specimens. Mol Cancer Ther 2007;6:1223-9.

94. Coghlin CL, Smith LJ, Bakar S, et al. Quantitative analysis of tumor in bronchial biopsy specimens. J Thorac Oncol 2010:5:448-52.

95. Garcia-Olivé I, Monsó E, Andreo F, et al. Endobronchial ultrasound-guided transbronchial needle aspiration for identifying EGFR mutations. Eur Respir J 2010;35:391-5

96. Fassina A, Gazziero A, Zardo D, et al. Detection of EGFR and KRAS mutations on trans-thoracic needle aspiration of lung nodules by high resolution melting analysis. J Clin Pathol 2009;62:1096-102.

97. Smirnov DA, Zweitzig DR, Foulk BW, et al. Global gene expression profiling of circulating tumor cells. Cancer Res 2005:65:4993-7.

98. Marchetti A, Felicioni L, Buttitta F. Assessing EGFR mutations. N Engl J Med 2006:354:526-8; author reply -8.

99. Dufort S, Richard MJ, Lantuejoul S, et al. Pyrosequencing, a method approved to detect the two major EGFR mutations for anti EGFR therapy in NSCLC. J Exp Clin Cancer Res 2011:30:57.

100. Querings S, Altmüller J, Ansén S, et al. Benchmarking of mutation diagnostics in clinical lung cancer specimens. PLoS One 2011;6:e19601.

101. Inoue A, Suzuki T, Fukuhara T, et al. Prospective phase II study of gefitinib for chemotherapy-naive patients with advanced non-small-cell lung cancer with epidermal growth factor receptor gene mutations. J Clin Oncol 2006;24:3340-6.

102. Nagai Y, Miyazawa H, Huqun, et al. Genetic heterogeneity of the epidermal growth factor receptor in non-small cell lung cancer cell lines revealed by a rapid and sensitive detection system, the peptide nucleic acid-locked nucleic acid PCR clamp. Cancer Res 2005:65:7276-82.

103. Sequist LV, Lynch TJ. EGFR tyrosine kinase inhibitors in lung cancer: an evolving story. Annu Rev Med 2008;59:429-42.

104. Sasaki H, Shimizu S, Endo K, et al. EGFR and erbB2 mutation status in Japanese lung cancer patients. Int J Cancer 2006;118:180-4.

105. Matsukuma S, Yoshihara M, Kasai F, et al. Rapid and simple detection of hot spo point mutations of epidermal growth factor receptor, BRAF, and NRAS in cancers using the loop-hybrid mobility shift assay. J Mol Diagn 2006;8:504-12.

106. Molina-Vila MA, Bertran-Alamillo J, Reguart N, et al. A sensitive method for detecting EGFR mutations in non-small cell lung cancer samples with few tumor cells. J Thorac Oncol 2008;3:1224-35.

107. Kawada I, Soejima K, Watanabe H, et al. An alternative method for screening EGFR mutation using RFLP in non-small cell lung cancer patients. $J$ Thorac Oncol 2008; 3:1096-103

108. Janne PA, Borras AM, Kuang Y, et al. A rapid and sensitive enzymatic method for epidermal growth factor receptor mutation screening. Clin Cancer Res 2006:12:751-8.

109. Asano H, Toyooka S, Tokumo M, et al. Detection of EGFR gene mutation in lung cancer by mutant-enriched polymerase chain reaction assay. Clin Cancer Res 2006:12:43-8.

110. Kim TY, Han SW, Bang YJ. Chasing targets for EGFR tyrosine kinase inhibitors in non-small-cell lung cancer: Asian perspectives. Expert Rev Mol Diagn 2007:7:821-36.

111. Fukui T, Ohe $\mathrm{Y}$, Tsuta $\mathrm{K}$, et al. Prospective study of the accuracy of EGFR mutational analysis by high-resolution melting analysis in small samples obtained from patients with non-small cell lung cancer. Clin Cancer Res 2008;14:4751-7.

112. Nomoto K, Tsuta K, Takano T, et al. Detection of EGFR mutations in archived cytologic specimens of non-small cell lung cancer using high-resolution melting analysis. Am J Clin Pathol 2006;126:608-15.

113. Yung TK, Chan KC, Mok TS, et al. Single-molecule detection of epidermal growth factor receptor mutations in plasma by microfluidics digital PCR in non-small cell lung cancer patients. Clin Cancer Res 2009;15:2076-84.

114. Tan R, Brzoska P. Direct detection of rare circulating tumor cells in blood by castPCR. J Biomol Tech 2010;21(3 Suppl):S30.

115. Yu J, Kane S, Wu J, et al. Mutation-specific antibodies for the detection of EGFR mutations in non-small-cell lung cancer. Clin Cancer Res 2009:15:3023-8.

116. Kato Y, Peled N, Wynes MW, et al. Novel epidermal growth factor receptor mutation-specific antibodies for non-small cell lung cancer: immunohistochemistry as a possible screening method for epidermal growth factor receptor mutations. J Thorac Oncol 2010;5:1551-8. 